\title{
Adsorption kinetics of polyethylene glycol from aqueous solution onto activated carbon
}

\author{
Chiung-Fen Chang ${ }^{\mathrm{a}}$, Ching-Yuan Chang ${ }^{\mathrm{a}, *}$, Wolfgang Höll ${ }^{\mathrm{b}}$, Markus Ulmer ${ }^{\mathrm{c}}$, \\ Yi-Hung Chen ${ }^{\mathrm{a}}$, Hans-Jügen Groß ${ }^{\mathrm{c}}$ \\ ${ }^{a}$ Graduate Institute of Environmental Engineering, National Taiwan University, 71 Chou-Shan Road, Taipei 106, Taiwan \\ ${ }^{\mathrm{b}}$ Forschungszentrum Karlsruhe Technik und Umwelt, Institute for Technical Chemistry, Section WGT, P.O. Box 3640, \\ Karlsruhe D-76021, Germany \\ ${ }^{\mathrm{c}}$ DVGW-Technologiezentrum Wasser (TZW) Karlsruhe, Heinrich-Sontheimer-Laboratory for Water Technology, Karlsruher Str. 84, \\ Karlsruhe D-76139, Germany
}

Received 1 September 2003; received in revised form 13 February 2004; accepted 4 March 2004

\begin{abstract}
The adsorption equilibrium and kinetics of polyethylene glycol (PEG) in three aqueous systems were examined in this study. Langmuir isotherm was used to satisfactorily predict the adsorption capacity of PEG on activated carbon F-400 and applied to the investigation of adsorption kinetics. The surface diffusion, pore diffusion, and branched pore kinetics models successfully described the adsorption behavior of PEG on F-400 in the completely stirred tank reactor. The pore diffusion coefficients obtained from the pore diffusion model were compared with those computed by the experimental data of the short fixed-bed reactor combined with the assumption of non-hindered pore diffusion. In addition, the effects of initial concentrations of PEG and the relative importance of external and internal mass transfers for the adsorption were also taken into account and discussed in this study.
\end{abstract}

(C) 2004 Elsevier Ltd. All rights reserved.

Keywords: Polyethylene glycol; Activated carbon; Adsorption isotherm; Adsorption kinetics; Film mass transfer; Intraparticle mass transfer

\section{Introduction}

Printed wiring board (PWB) plays a decisive important role in the electronic systems, which are essential to the improvement in the information and communication technologies. Therefore, many countries put a lot of emphasis on the development of the PWB industry in the recent decade and result in a huge amount of wastewater. To effectively treat the wastewater is a challenge to be deal with nowadays. Polyethylene glycol (PEG) is used as the disperse agent in the electroplating solution and at low concentration of $0-50 \mathrm{~g} / \mathrm{m}^{3}$ [1]. The previous study showed that it is feasible to use the

\footnotetext{
*Corresponding author. Tel./fax: + 886-2-2363-8994.

E-mail address: cychang3@ntu.edu.tw (C.-Y. Chang).
}

adsorption process to remove PEG from the electroplating solution, thereby, achieving the goal of recycling the electroplating bath [2]. In addition, PEG is one of non-ionic surfactants and widely used in the industries, such as metal forming, cosmetics, food, etc., due to the advantage that they can be compatible with ionic and amphoteric surfactants. Therefore, PEG is one of abundant organic surfactants commonly found in the industrial wastewater, and needs to be dealt with.

Adsorption using activated carbon (AC) for removing the organics from the aqueous solution is an effective separation technology and widely applied in the water treatment. There are two common adsorption designs for wastewater treatment, namely, stirred-batch- and fixed-bed adsorber systems. The former is certainly simple and allowed to reach equilibrium quickly. In 


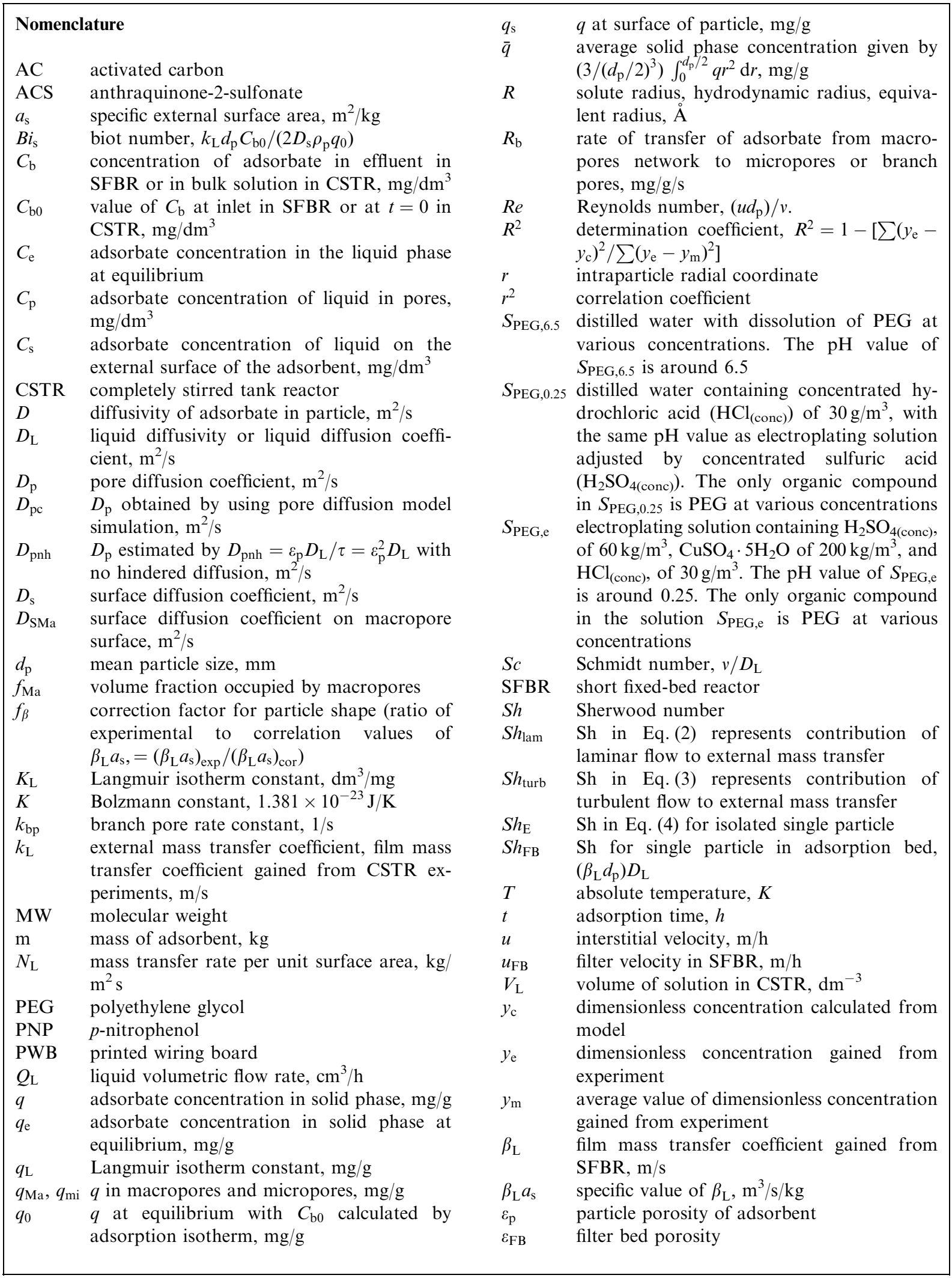




\begin{tabular}{|llll|}
\hline$\mu$ & dynamic viscosity, cp & $\rho_{\mathrm{p}}$ & apparent particle density, $\mathrm{kg} / \mathrm{m}^{3}$ \\
$\mu_{\mathrm{B}}$ & $\mu$ of solvent, cp & $\rho_{\mathrm{s}}$ & average true particle density, $\mathrm{kg} / \mathrm{m}^{3}$ \\
$\nu$ & kinetic viscosity, $\mu / \rho, \mathrm{m}^{2} / \mathrm{s}$ & $\tau$ & tortuosity \\
$\rho$ & density, $\mathrm{kg} / \mathrm{m}^{3}$ & $\delta$ & Nernst film thickness \\
$P_{\mathrm{FB}}$ & filter bed density, $\mathrm{kg} / \mathrm{m}^{3}$ & & \\
& & \\
\hline
\end{tabular}

contrast, the latter involves the mass transfer, which consists of two main mechanisms: external- (i.e., film diffusion) and internal (e.g., surface diffusion, pore diffusion, and a combination thereof) mass transfers. The study of stirred-batch adsorption kinetics can provide the design parameters of the internal mass transfer coefficients (surface diffusion coefficient, $D_{\mathrm{s}}$, pore diffusion coefficient, $D_{\mathrm{p}}$ ), which are also greatly related to fixed-bed adsorption systems.

To economically design the adsorption process for the removal of $\mathrm{PEG}$, it is necessary to know the specific parameters, such as isotherm and kinetic constants, related to the adsorption of PEG on the activated carbon. The aims of this work were, therefore, (1) to study the adsorption equilibrium and kinetics of PEG from three different aqueous solutions onto activated carbon, (2) to evaluate the diffusivities in the liquid and carbon phases, and (3) to elucidate the relative importance of external and internal mass transfers for the development of adsorption.

\section{Materials and methods}

\subsection{Adsorbate}

Reagent-grade PEG supplied by Merck was applied in this study. The average molecular weight (MW) of PEG is 6000 with an MW range from 5000 to 7000, and belongs to polydisperse system. The standard compounds (reagent-grade supplied by Merck) used to obtain the correction factor of particle shape, $f_{\beta}$, in the short fixed-bed reactor (SFBR) experiments are p-nitrophenol (PNP) and anthraquinone-2-sulfonate (ACS).

\subsection{Adsorbent}

Activated carbon, F-400 (Calgon), with a particle size range between 0.42 and $1.68 \mathrm{~mm}$ was used as the adsorbent. The mean particle size of AC, $d_{\mathrm{p}}=1.04 \mathrm{~mm}$, was calculated from the sieve analysis of the representative samples obtained by using a rotating sample-splitting device by means of the weight percentages of particles in the different sieve sizes. The physical characteristics of F-400 are summarized in Table 1. The pretreatment of the adsorbent comprised several steps. Firstly, the adsorbent is washed with
Table 1

Physical characteristics of F 400

\begin{tabular}{|c|c|}
\hline Property & F 400 \\
\hline Mesh size & $12-40$ \\
\hline Average particle diameter, $d_{\mathrm{p}}(\mathrm{mm})$ & 1.044 \\
\hline Langmuir specific surface area ${ }^{\mathrm{a}}\left(\mathrm{m}^{2} / \mathrm{g}\right)$ & 1363 \\
\hline Total pore volume ${ }^{\mathrm{a}}\left(\mathrm{cm}^{3} / \mathrm{g}\right)$ & 0.616 \\
\hline Specific external surface area ${ }^{\mathrm{b}}, a_{\mathrm{s}}\left(\mathrm{m}^{2} / \mathrm{kg}\right)$ & 5.76 \\
\hline Average true particle density ${ }^{\mathrm{a}}, \rho_{\mathrm{s}}\left(\mathrm{kg} / \mathrm{m}^{3}\right)$ & 2180 \\
\hline Apparent particle density ${ }^{\mathrm{c}}, \rho_{\mathrm{p}}\left(\mathrm{kg} / \mathrm{m}^{3}\right)$ & 1000 \\
\hline Filter bed density ${ }^{\mathrm{d}}, \rho_{\mathrm{FB}}\left(\mathrm{kg} / \mathrm{m}^{3}\right)$ & 530 \\
\hline Particle porosity ${ }^{\mathrm{e}}, \varepsilon_{\mathrm{p}}(-)$ & 0.54 \\
\hline Filter bed porosity ${ }^{\mathrm{d}, \mathrm{f}}, \varepsilon_{\mathrm{FB}}(-)$ & 0.47 \\
\hline Average pore diameter ${ }^{\mathrm{g}}(\AA)$ & 18 \\
\hline
\end{tabular}

${ }^{\mathrm{a}}$ Data from the surface area determined by $\mathrm{N}_{2}$ adsorption at $77 \mathrm{~K}$ in the volumetric equipment, ASAP 2010.

${ }^{\mathrm{b}}$ Assumed as spherical particle and calculated using $a_{\mathrm{s}}=$ $6 /\left(\rho_{\mathrm{p}} d_{\mathrm{p}}\right)$.

${ }^{\mathrm{c}}$ Data from the experiments of pycnometer.

${ }^{\mathrm{d}}$ In a water-filled bed.

${ }^{\mathrm{e}}$ Calculated using $\varepsilon_{\mathrm{p}}=1-\left(\rho_{\mathrm{p}} / \rho_{\mathrm{s}}\right)$.

${ }^{\mathrm{f}}$ Calculated using $\varepsilon_{\mathrm{FB}}=1-\left(\rho_{\mathrm{FB}} / \rho_{\mathrm{p}}\right)$.

${ }^{\mathrm{g}}$ Calculated by $4 \times$ total pore volume/Langmuir specific surface area.

distilled water to remove the crushed carbon. Secondly, it is dried at $383 \mathrm{~K}$ in a vacuum oven overnight and then stored in the desiccator. Finally, it is wetted in the specific solutions under vacuum before the adsorption experiments.

\subsection{Aqueous systems}

Three kinds of aqueous solvents were used to investigate the adsorption behaviors of the PEG by F400 as listed below:

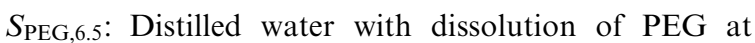
various concentrations. The $\mathrm{pH}$ value of $S_{\mathrm{PEG}, 6.5}$ is around 6.5 .

$S_{\text {PEG } 0.25}$ : Distilled water containing concentrated hydrochloric acid $\left(\mathrm{HCl}_{\text {(conc) }}\right)$ of $30 \mathrm{~g} \mathrm{~m}^{-3}$, with the same $\mathrm{pH}$ value as electroplating solution adjusted by concentrated sulfuric acid $\left(\mathrm{H}_{2} \mathrm{SO}_{4(\mathrm{conc})}\right)$. The only organic compound in $S_{\mathrm{PEG}, 0.25}$ is PEG at various concentrations. 
Table 2

Some properties of PEG in various aqueous solutions

\begin{tabular}{|c|c|c|c|}
\hline Solution & $\begin{array}{l}D_{\mathrm{L}} \text { at } 298 \mathrm{~K} \\
\left(10^{-10} \mathrm{~m}^{2} / \mathrm{s}\right)\end{array}$ & $\begin{array}{l}D_{\mathrm{L}} \times \varepsilon_{\mathrm{p}}^{2} \\
\left(10^{-10} \mathrm{~m}^{2} / \mathrm{s}\right)\end{array}$ & $\begin{array}{l}\text { Hydrodynamic } \\
\text { diameter }^{\mathrm{a}}(\AA)\end{array}$ \\
\hline$S_{\text {PEG }, 6.5}$ & $1.15^{\mathrm{b}}$ & 0.34 & 38 \\
\hline$S_{\text {PEG }, 0.25}$ & $1.03^{\mathrm{c}}$ & 0.30 & 34 \\
\hline$S_{\mathrm{PEG}, \mathrm{e}}$ & $0.90^{\mathrm{c}}$ & 0.26 & 30 \\
\hline
\end{tabular}

${ }^{\mathrm{a}}$ Calculated by the Stokes-Einstein equation.

${ }^{\mathrm{b}}$ Predicted value with assumption of monodisperse system of PEG [10].

${ }^{\mathrm{c}}$ Experimental data from SFBR.

$S_{\mathrm{PEG}, \mathrm{e}}$ : Electroplating solution containing $\mathrm{H}_{2} \mathrm{SO}_{4}$ (conc) of $60 \mathrm{~kg} / \mathrm{m}^{3}, \mathrm{CuSO}_{4} \cdot 5 \mathrm{H}_{2} \mathrm{O}$ of $200 \mathrm{~kg} / \mathrm{m}^{3}$, and $\mathrm{HCl}_{\text {(conc) }}$ of $30 \mathrm{~g} / \mathrm{m}^{3}$. The $\mathrm{pH}$ value of $S_{\text {PEG,e }}$ is around 0.25 . The only organic compound in the solution $S_{\mathrm{PEG}, \mathrm{e}}$ is $\mathrm{PEG}$ at various concentrations.

Some properties of PEG in various aqueous solutions are listed in Table 2.

\subsection{Analytical measurements}

For measurements of adsorption equilibria and experiments in a completely stirred tank reactor (CSTR), all samples were filtrated through a $0.45 \mu \mathrm{m}$ membrane, prior to the analysis. PEG concentrations were measured by means of a total organic carbon analyzer (O.I.C. M-700). For experiments in an SFBR reactor another Carbon Analyzer (Dohrmann DC-80) and a UV spectrophotometer (Perkin-Elmer UV/VIS Lambda 3) were employed. The wavelengths used in UV spectrophotometry for PNP and ACS analyses in distilled water are 315 and $253 \mathrm{~nm}$, respectively.

\subsection{Adsorption equilibrium}

For evaluation of the adsorption equilibrium, $0.1 \mathrm{dm}^{3}$ matrix solutions containing PEG of various initial concentrations were mixed with $0.05 \mathrm{~g}$ of adsorbent and shaken at $298 \mathrm{~K}$ until the concentrations of filtrate did not change more than 3\%. The initial concentrations of PEG in different levels are specially designed to obtain adsorption isotherms covering suitable concentration ranges, which allow the interpretation of the experimental data obtained in the following kinetic experiments (i.e., data gained from the CSTR). Because it is preferable to use the weight concentration units for investigating the removal efficiency of the target substance in wastewater treatment, concentrations are given with units in $\mathrm{g} / \mathrm{m}^{3}$ (or mole $/ \mathrm{m}^{3}$ ) and $\mathrm{g} / \mathrm{kg}$ (or mole $/ \mathrm{kg}^{3}$ ) for the liquid and solid phases, respectively.

\subsection{SFBR experiments}

SFBR was used to investigate the external mass transfer coefficient (i.e., film transfer coefficient), $\beta_{\mathrm{L}}$, which is determined by means of the plateau concentration of the first part of the breakthrough curve of the operation of the reactor [3]. The concentration of the solution fed into the SFBR should be kept constant and low enough being not to cause intraparticle diffusion. In this study, the length and diameter of the SFBR were 20 and $2 \mathrm{~cm}$, respectively. The temperature for the solutions containing the organic additive and standard compounds were kept constant at 298 and $293 \mathrm{~K}$, respectively, which were carefully controlled by noting that the effect of the temperature is significant for the kinetics of adsorption [4]. To obviate air bubbles in the carbon bed, the column was packed under specific wetting solutions.

\subsection{CSTR experiments}

For the CSTR experiments, a basket reactor of $3.705 \mathrm{dm}^{3}$ was adopted to this system to avoid the attrition of adsorbent, which may be encountered in the slurry reactor. The various stirrer revolutions from 300 to $700 \mathrm{rpm}$ were examined in order to ensure the complete mixing and to reduce the film resistance to a minimum. The ratio of adsorbent mass to solution volume was $1 \mathrm{~g} / \mathrm{dm}^{3}$ and the temperature was adjusted and controlled at $298 \mathrm{~K}$. The initial concentrations of PEG were from 50 to $450 \mathrm{~g} / \mathrm{m}^{3}$.

\section{Results and discussion}

\subsection{Adsorption isotherm}

Hydrophobic attraction mainly contributes the adsorption of the non-polar segments of PEG on the hydrophobic surface of F-400, resulting in the removal of PEG from the aqueous phase. At lower coverage of PEG on F-400, the conformation of PEG at the adsorbing interface is isolated and the lateral interaction between adsorbed PEG can be ignored. The lateral interaction becomes significant with increasing coverage of PEG on F-400. The Langmuir isotherm can be applied to describe the adsorption equilibrium of PEG in $S_{\text {PEG,e }}$ solution, which was previously performed [2]. The mathematical relationship of the isotherm is:

$q_{\mathrm{e}}=\frac{q_{\mathrm{L}} K_{\mathrm{L}} C_{\mathrm{e}}}{1+K_{\mathrm{L}} C_{\mathrm{e}}}$.

In Eq. (1), $q_{\mathrm{e}}$ and $C_{\mathrm{e}}$ are the adsorbate concentrations in solid and liquid phases at equilibrium, respectively. $q_{\mathrm{L}}$ and $K_{\mathrm{L}}$ are the Langmuir isotherm constants. All isotherm constants and equilibria for the adsorption systems with solutions of $S_{\mathrm{PEG}, 6.5}, S_{\mathrm{PEG}, \mathrm{e}}$, and $S_{\mathrm{PEG}, 0.25}$ 
are summarized in Table 3 and illustrated in Fig. 1, respectively.

At equilibrium concentrations lower than $0.0025 \mathrm{~mol} /$ $\mathrm{m}^{3}$, the uptake of PEG on F-400 seems similar in three solutions, interpreting that the effect of ionic strength and the $\mathrm{pH}$ value of the solution on the adsorption of isolated PEG on F-400 was negligible. However, when the adsorption approaches the plateau, the effects of the properties of solution on adsorption of PEG become significant, resulting in the reduction of adsorption capacity at high concentrations of PEG in $S_{\mathrm{PEG}, \mathrm{e}}$ and $S_{\text {PEG,0.25 }}$ which exhibit high ionic strength and lower $\mathrm{pH}$ value, respectively. The hydrophilic tendency of the nonionic surfactants is essentially due to oxygen in the molecule, which can be hydrated by hydrogen bonding to water molecules [5]. Therefore, the hydrated chain of PEG in the conformation of coil spreads into the aqueous phase and causes great steric repulsion. In addition, the copper (II) may bond to the oxygen and form the PEG-copper (II) complex in $S_{\mathrm{PEG}, \mathrm{e}}$, which causes the electrostatic repulsion between adsorbed complexes and significantly reduces the adsorption capacity in the plateau. Although the high ionic strength can bring the shield effect to lower the electrostatic repulsion between the complexes in $S_{\mathrm{PEG}, \mathrm{e}}$, the adsorption capacity at plateau portion may be reduced dominantly by the strong steric repulsion. Therefore, both electrostatic and steric repulsions play important roles on the adsorption of PEG in $S_{\mathrm{PEG}, \mathrm{e}}$ and $S_{\mathrm{PEG}, 0.25 \text {, }}$ then reducing the adsorption capacity in the plateau portion.

\subsection{External mass transfer in SFBR and liquid diffusivity}

There are two possible formulations of the SFBR model, the plug-flow film diffusion and dispersed-flow diffusion models, respectively [3]. The value of the film mass transfer coefficient $\left(\beta_{\mathrm{L}}\right)$ in the SFBR calculated from the former was only $5 \%$ lower than that from the latter [6]. Therefore, the plug-flow film diffusion, due to its simplicity, is chosen in this study as the main model to obtain $\beta_{\mathrm{L}}$ values by neglecting the axial dispersion. In addition, the Gnielinski correlations [7], which are suitable for $S c$ (Schmidt number) $<12,000$ and $S c R e$ (Reynolds number) $>500$, are adopted in this study to calculate the liquid diffusivity $\left(D_{\mathrm{L}}\right)$ by noting the good agreement with the measured data [6]. The Gnielinski correlations, which assume the spherical shape of particles, are

$$
\begin{aligned}
& S h_{\mathrm{lam}}=0.664 S c^{1 / 3} R e^{1 / 2} \\
& S h_{\mathrm{turb}}=\frac{0.037 R e^{0.8} S c}{1+2.443 R e^{-0.1}\left(S c^{2 / 3}-1\right)} \\
& S h_{\mathrm{E}}=2+\sqrt{S h_{\mathrm{lam}}^{2}+S h_{\mathrm{turb}}^{2}}
\end{aligned}
$$

$S h_{\mathrm{FB}}=\frac{\beta_{\mathrm{L}} d_{\mathrm{P}}}{D_{\mathrm{L}}}=\left[1+1.5\left(1-\varepsilon_{\mathrm{FB}}\right)\right] S h_{\mathrm{E}}$.

In the above equations, the dimensionless parameters are defined as: $\operatorname{Re}=\left(d_{\mathrm{p}} u\right) / v$ with $u=u_{\mathrm{FB}} / \varepsilon_{\mathrm{FB}}, S c=$ $v / D_{\mathrm{L}}$, and $S h_{\mathrm{FB}}=\left(\beta_{\mathrm{L}} d_{\mathrm{p}}\right) / D_{\mathrm{L}}$. Typical values of $u_{\mathrm{FB}}, \varepsilon_{\mathrm{FB}}$, and $d_{\mathrm{p}}$ in this study are $5,8,10,15$, and $20 \mathrm{~m} / \mathrm{h}\left(u_{\mathrm{FB}}\right)$, $0.47\left(\varepsilon_{\mathrm{FB}}\right)$, and $1.04 \mathrm{~mm}\left(d_{\mathrm{p}}\right)$, respectively. The density and viscosity of $S_{\mathrm{PEG}, 6.5}, S_{\mathrm{PEG}, 0.25}$, and $S_{\mathrm{PEG}, \mathrm{e}}$ are $998.2 \mathrm{~kg} / \mathrm{m}^{3}$ and $1.005 \mathrm{cp} \mathrm{[8],} 1050 \mathrm{~kg} / \mathrm{m}^{3}$ and $1.24 \mathrm{cp}$, and $1130 \mathrm{~kg} / \mathrm{m}^{3}$ and $1.64 \mathrm{cp}$, respectively, at $293 \mathrm{~K}$.

The fundamental mathematical relationship for evaluation of the SFBR results assuming plug-flow film diffusion is as follows:

$\left.\beta_{\mathrm{L}}\right|_{t \rightarrow 0}=-\frac{Q_{\mathrm{L}}}{m a_{\mathrm{S}}} \ln \frac{C_{\mathrm{b}}}{C_{\mathrm{b} 0}}$,

where $\beta_{\mathrm{L}}, Q_{\mathrm{L}}, m$, and $a_{\mathrm{s}}$ are the film mass transfer coefficient $(\mathrm{m} / \mathrm{s})$, liquid flow rate $\left(\mathrm{cm}^{3} / \mathrm{s}\right)$, mass of the adsorbent applied, and specific external surface area of the adsorbent, respectively. The $C_{\mathrm{b}}$ and $C_{\mathrm{b} 0}$ represent the bulk concentrations of effluent at time $t$, and of inlet, respectively. The term $\beta_{\mathrm{L}} a_{\mathrm{s}}$ may be called the specific film mass transfer coefficient. Because the Gnielinski correlations assume the spherical shape of particles, correction with respect to the geometry of the particles is necessary for non-regularly shaped particles. The correction factor, $f_{\beta}$, depending on the shape of the adsorbent, can be determined by the difference between the experimental data and the Gnielinski correlation results of known adsorbates (i.e., standard compounds in this study) as follows [3]:

$f_{\beta}=\frac{\left(\beta_{\mathrm{L}} a_{\mathrm{S}}\right)_{\exp }}{\left(\beta_{\mathrm{L}} a_{\mathrm{S}}\right)_{\mathrm{cor}}}$

In Eq. (7), the indices exp and cor indicate the values obtained from the experimental data, and those calculated from the Gnielinski correlations, respectively. The value of $f_{\beta}$ for F-400 is 2.18, averaged from 2.11 of PNP and 2.25 of ACS, of which the values were calculated from the reported $D_{\mathrm{L}}$ values of PNP $\left(7.8 \times 10^{-10} \mathrm{~m}^{2} / \mathrm{s}\right)$ and ACS $\left(6.4 \times 10^{-10} \mathrm{~m}^{2} / \mathrm{s}\right)$ [4]. It signifies that the relative errors of the $D_{\mathrm{L}}$ recalculated via Eqs. (2)-(5) with $f_{\beta}$, which employs $\beta_{\mathrm{L}}=$ $\left(\beta_{\mathrm{L}} a_{\mathrm{s}}\right)_{\exp } /\left(f_{\beta}\left(a_{\mathrm{s}}\right)_{\mathrm{cor}}\right)$, and without $f_{\beta}$, which gives $\beta_{\mathrm{L}}=$ $\left(\beta_{\mathrm{L}} a_{\mathrm{S}}\right)_{\exp } /\left(a_{\mathrm{s}}\right)_{\text {cor }}$ to the reference value $\left(6.4 \times 10^{-10} \mathrm{~m}^{2} / \mathrm{s}\right)$ for ACS are approximately $4 \%$ and $39 \%$, respectively. Therefore, the effect of the geometry of the adsorbent has to be taken into account in the calculation of $D_{\mathrm{L}}$ via Eqs. (2)-(5).

Fig. 2 presents the ratio of $C_{\mathrm{b}} / C_{\mathrm{b} 0}$ for the PEG adsorption from $S_{\text {PEG,e }}$ in the SFBR as a function of time. For the A-B portion of the breakthrough curve, the effluent concentration increases only slightly after point $\mathrm{A}$ as a result of the gradual displacement of the lower MW fractions by the higher MW fractions present in the polydisperse system of PEG. Therefore, the 
Table 3

Langmuir isotherm constants and transport quantities of PEG in the aqueous system

\begin{tabular}{|c|c|c|c|c|c|c|c|c|c|c|}
\hline \multirow[t]{2}{*}{ Condition } & \multicolumn{3}{|c|}{ Isotherm constants } & \multirow{2}{*}{$\begin{array}{l}\text { Film mass } \\
\text { transfer } \\
\text { coefficient } \\
k_{\mathrm{L}}\left(10^{-5} \mathrm{~m} / \mathrm{s}\right)\end{array}$} & \multicolumn{6}{|c|}{ Internal diffusion coefficients } \\
\hline & $q_{\mathrm{L}}(\mathrm{mole} / \mathrm{kg})$ & $K_{\mathrm{L}}\left(\mathrm{m}^{3} /\right.$ mole $)$ & $r^{2}$ & & $D_{\mathrm{s}}\left(\mathrm{m}^{2} / \mathrm{s}\right)$ & $R^{2 \mathrm{a}}$ & $D_{\mathrm{p}}\left(\mathrm{m}^{2} / \mathrm{s}\right)$ & $R^{2 \mathrm{a}}$ & $\begin{array}{l}D_{\mathrm{Sma}}\left(\mathrm{m}^{2} / \mathrm{s}\right) \\
k_{\mathrm{bp}}(1 / \mathrm{s}), f_{\mathrm{Ma}}\end{array}$ & $R^{2 \mathrm{a}}$ \\
\hline $\begin{array}{l}\text { Case I: Initial } \\
\text { concentration } \\
\left(C_{\mathrm{b} 0}\right)=50 \mathrm{~g} / \mathrm{m}^{3} \text { in bright } \\
\text { electroplating solution, } \\
S_{\text {PEG,e }}\end{array}$ & $0.064^{\mathrm{b}}$ & $1051^{\mathrm{b}}$ & 0.9798 & 5.26 & $4.5 \times 10^{-12}$ & 0.98 & $2.9 \times 10^{-9}$ & 0.98 & $\begin{array}{l}1.06 \times 10^{-13} \\
1.99 \times 10^{-6} \\
0.67\end{array}$ & 0.999 \\
\hline $\begin{array}{l}\text { Case II: } C_{\mathrm{b} 0}=50 \mathrm{~g} / \mathrm{m}^{3} \text { in } \\
\text { aqueous solution of } \\
S_{\mathrm{PEG}, 6.5} \text { at } \mathrm{pH}=6.5\end{array}$ & 0.337 & 83.59 & 0.8642 & 10.0 & $2.2 \times 10^{-13}$ & 0.99 & $6.2 \times 10^{-9}$ & 0.98 & $\begin{array}{l}2.0 \times 10^{-13} \\
9.0 \times 10^{-6} \\
0.92\end{array}$ & 0.999 \\
\hline $\begin{array}{l}\text { In aqueous solution of } \\
S_{\text {PEG } 0.25} \text { at } \mathrm{pH}=0.25\end{array}$ & 0.093 & 336 & 0.8164 & & & & & & & \\
\hline Case III: $C_{\mathrm{b} 0}=50 \mathrm{~g} / \mathrm{m}^{3}$ & & & & 9.55 & $1.3 \times 10^{-13}$ & 0.99 & $7.7 \times 10^{-9}$ & 0.99 & $\begin{array}{l}5.3 \times 10^{-13} \\
2.1 \times 10^{-5} \\
0.96\end{array}$ & 0.99 \\
\hline Case IV: $C_{\mathrm{b} 0}=100 \mathrm{~g} / \mathrm{m}^{3}$ & & & & 6.83 & $2.5 \times 10^{-13}$ & 0.99 & $3.8 \times 10^{-9}$ & 0.99 & $\begin{array}{l}3.4 \times 10^{-13} \\
1.4 \times 10^{-5} \\
0.99\end{array}$ & 0.99 \\
\hline Case $V: C_{\mathrm{b} 0}=200 \mathrm{~g} / \mathrm{m}^{3}$ & & & & 3.55 & $3.9 \times 10^{-13}$ & 0.99 & $1.6 \times 10^{-9}$ & 1.00 & $\begin{array}{l}1.2 \times 10^{-13} \\
1.3 \times 10^{-5} \\
0.99\end{array}$ & 0.99 \\
\hline Case VI: $C_{\mathrm{b} 0}=450 \mathrm{~g} / \mathrm{m}^{3}$ & & & & 0.78 & $1.8 \times 10^{-12}$ & 0.97 & $1.1 \times 10^{-9}$ & 0.98 & $\begin{array}{l}1.5 \times 10^{-13} \\
1.3 \times 10^{-6} \\
0.25\end{array}$ & 0.99 \\
\hline
\end{tabular}

${ }^{\mathrm{a}} R^{2}=1-\left[\sum\left(y_{\mathrm{e}}-y_{\mathrm{c}}\right)^{2} / \sum\left(y_{\mathrm{e}}-y_{\mathrm{m}}\right)^{2}\right]$.

${ }^{\mathrm{b}}$ Ref. [2]. 


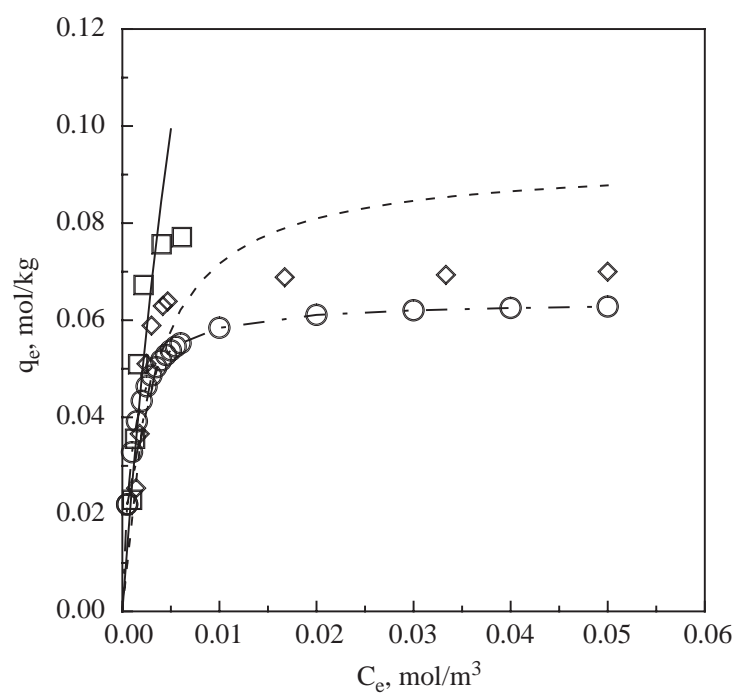

Fig. 1. The simulation of Langmuir isotherm for polyethylene glycol (PEG) adsorption in aqueous system on activated carbon F-400. $(\square)$ and $(-),(\diamond)$ and $(--)$, and $(\bigcirc)$ and $(--)$ : experimental data and simulation results at $298 \mathrm{~K}$ in aqueous system of $S_{\mathrm{PEG}, 6.5}$ at $\mathrm{pH}=6.5$; aqueous system of $S_{\mathrm{PEG}, 0.25}$ at $\mathrm{pH}=0.25$ adjusted by concentrated $\mathrm{H}_{2} \mathrm{SO}_{4}$; and electroplating solution of $S_{\mathrm{PEG}, \mathrm{e}}$, respectively.

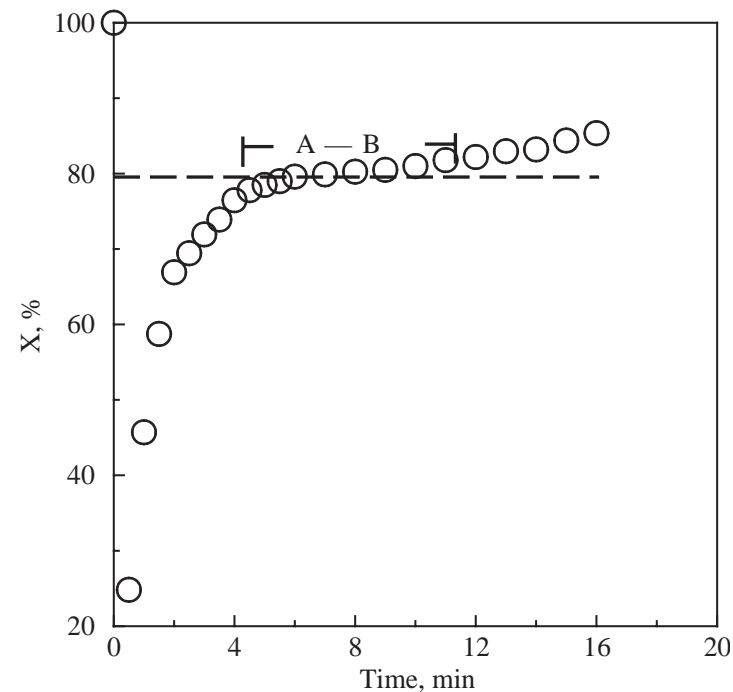

Fig. 2. Variation of dimensionless effluent concentration $(X$, with $\left.X=C_{\mathrm{b}}(t) / C_{\mathrm{b} 0}\right)$ with time for experiments using SFBR. (O): Experimental data of PEG adsorption in $S_{\text {PEG,e }}$ at filter velocity $u_{\mathrm{FB}}=10 \mathrm{~m} / \mathrm{h}$.

$C_{\mathrm{b}} / C_{\mathrm{b} 0}$ in the plateau portion (A-B) was viewed as staying constant, which was used to compute the experimental value of $\beta_{\mathrm{L}} a_{\mathrm{s}}$ from Eq. (6). Sequentially, the Gnielinski correlations of Eqs. (2)-(5) were used to calculate the liquid diffusivity values of PEG in different solution, as shown in Table 2. A more detailed discussion of the calculations and the demonstration of its validity can be referred to our previous study [9]. The values of $D_{\mathrm{L}}$ from experiments in $S_{\mathrm{PEG}, \mathrm{e}}$ and $S_{\mathrm{PEG}, 0.25}$ are 0.9 and $1.03 \times 10^{-10} \mathrm{~m}^{2} / \mathrm{s}$, respectively. The $D_{\mathrm{L}}$ value of $S_{\text {PEG,6.5 }}$ can be obtained by the Stokes-Einstein equation combined with the assumption of monodisperse of PEG [10,11], and is equal to $1.15 \times 10^{-10} \mathrm{~m}^{2} / \mathrm{s}$.

\subsection{External mass transfer in CSTR}

In order to eliminate the film mass transfer resistance in the CSTR experiments, the influence of the intensity of mixing is examined, and illustrated in Fig. 3. When the speed of the stirrer rotation is higher than $500 \mathrm{rpm}$, the effect of film mass transfer resistance is greatly reduced and the internal mass transfer resistance is predominantly important for the adsorption kinetics. The external mass transfer coefficient $\left(k_{\mathrm{L}}\right)$ predominantly depends on the hydrodynamic flow across the surface of the adsorbent particles and other factors that may affect the diffusivity $D_{\mathrm{L}}$ and film thickness $\delta$. For short times, it can be assumed that adsorption is exclusively controlled by the external mass transfer and that the surface concentration $\left(C^{*}\right)$ is zero or negligible with respect to the bulk concentration $\left(C_{\mathrm{b}}\right)$. Hence, $k_{\mathrm{L}}$ can be calculated by

$\left.\ln \frac{C_{\mathrm{b}}}{C_{\mathrm{b} 0}}\right|_{t \rightarrow 0}=-k_{\mathrm{L}} \frac{m a_{\mathrm{S}}}{V_{\mathrm{L}}} t$

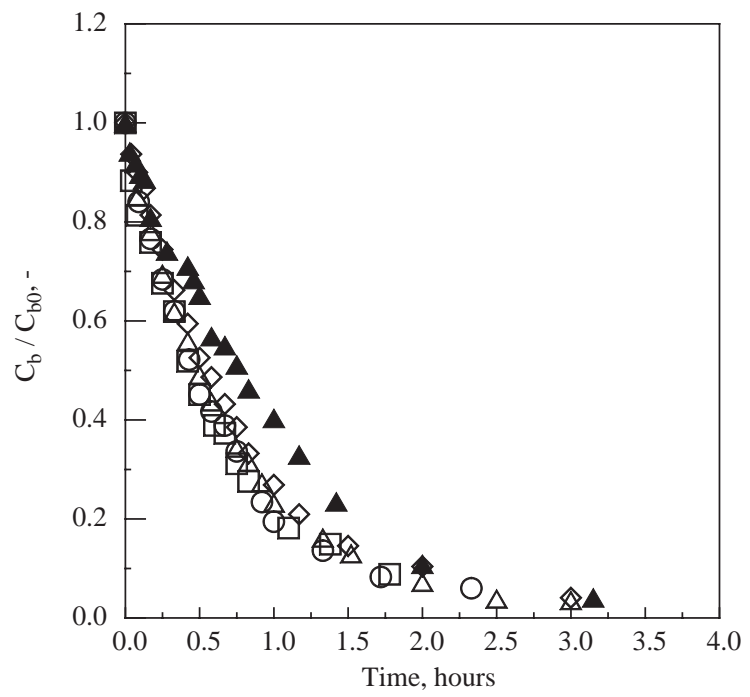

Fig. 3. Effects of stirring speed on the adsorption rate of PEG in $S_{\mathrm{PEG}, 6.5}$ on F-400 in CSTR. $(\mathbf{\Delta}),(\diamond),(\triangle),(\bigcirc)$, and $(\square)$ : experimental data with stirring speeds of $300,400,500,600$, and $700 \mathrm{rpm}$, respectively. 
In Eq. (8), $C_{\mathrm{b}}$ and $C_{\mathrm{b} 0}$ are the concentrations in the bulk solution at time $t=t$ and $0, k_{\mathrm{L}}$ is the external mass transfer coefficient, $m$ is the mass of the adsorbent employed, $a_{\mathrm{S}}$ is the specific external surface area of the adsorbent, $V_{\mathrm{L}}$ is the volume of the solution employed.

For the experiments performed under the stirring speed of $600 \mathrm{rpm}$, the results of $k_{\mathrm{L}}$ are listed in Table 3. Comparing $k_{\mathrm{L}}$ at the same $C_{\mathrm{b} 0}$ of $50 \mathrm{~g} / \mathrm{m}^{3}$ in $S_{\mathrm{PEG}, 6.5}$, $S_{\mathrm{PEG}, 0.25}$, and $S_{\mathrm{PEG}, \mathrm{e}}$, the mass transfer resistance of PEG was higher in the case of $S_{\mathrm{PEG}, \mathrm{e}}$ possessing the smaller $k_{\mathrm{L}}$ value. Besides, the $k_{\mathrm{L}}$ decreases with increasing $C_{\mathrm{b} 0}$ in the case of $S_{\mathrm{PEG}, 0.25}$ at various values of $C_{\mathrm{b} 0}$. Note that $k_{\mathrm{L}}$ resulting from Fick's first law is given by $k_{\mathrm{L}}=D_{\mathrm{L}} / \delta$, in which $\delta$ is the Nernst film thickness. The dependency of $k_{\mathrm{L}}$ on the concentration of PEG can be attributed to that $D_{\mathrm{L}}$ is inversely proportional to the viscosity of the solution according to Wilke and Chang correlation [12], and that the film thickness $(\delta)$ increases with increasing viscosity at the identical hydrodynamic operation conditions (flow rate in terms of $L / h$ ) [13-15]. Both phenomena lead to decreasing mass transfer coefficients at the increasing PEG concentration. Furthermore, it is also mentioned that the diffusion coefficient in liquid varies with the solute concentration [10].

\subsection{Modeling of the adsorption kinetics in CSTR}

In this study the intraparticle diffusion is interpreted as the surface diffusion, pore diffusion, and branched pore kinetics models, respectively. The intraparticle diffusion is usually dependent on the particle size of the adsorbent unless for very fine particles. However, the surface diffusion may strongly depend on the initial concentration of the solution. Thus, for modeling the usual cases, this study did not investigate the effect of the particle size but that of initial concentrations on the mass transfer of PEG. Mass transfer from the liquid to solid phases (i.e., external film transfer) for the three models can be described as [3]

$N_{\mathrm{L}}=-k_{\mathrm{L}}\left(C_{\mathrm{b}}-C_{\mathrm{s}}\right)=-D \frac{\partial C_{\mathrm{p}}}{\partial r}$ at $r=\frac{d_{\mathrm{p}}}{2}$.

In Eq. (9), $N_{\mathrm{L}}$ is the mass transfer rate per unit surface area, $C_{\mathrm{b}}$ is the adsorbate concentration in the bulk liquid, $C_{\mathrm{s}}$ is the value of $C_{\mathrm{b}}$ on the external surface of the adsorbent $\left(r=d_{\mathrm{p}} / 2\right), C_{\mathrm{p}}$ is the adsorbate concentration of liquid in the pores at $r=d_{\mathrm{p}} / 2, D$ is the diffusivity of adsorbate in particles, $r$ is the intraparticle radial coordinate. The governing Eqs. (10)-(13) listed are valid for the surface diffusion (Eq. (10)), pore diffusion (Eq. (11)), and branched pore kinetics models (Eqs. (12)-(13)), respectively. Additionally, the corresponding initial and boundary conditions are listed in Appendix. A more detailed discussion of these equations is given in the literature $[3,16,17]$

$$
\begin{aligned}
& \left(\frac{\varepsilon_{\mathrm{p}}}{\rho_{\mathrm{p}}}\right) \frac{\partial C_{\mathrm{p}}}{\partial t}+\frac{\partial q}{\partial t}=D_{\mathrm{s}}\left(\frac{\partial^{2} q}{\partial r^{2}}+\frac{2}{r} \frac{\partial q}{\partial r}\right), \\
& \varepsilon_{\mathrm{p}} \frac{\partial C_{\mathrm{p}}}{\partial t}+\rho_{\mathrm{p}} \frac{\partial q}{\partial t}=D_{\mathrm{p}}\left(\frac{\partial^{2} C_{\mathrm{p}}}{\partial r^{2}}+\frac{2}{r} \frac{\partial C_{\mathrm{p}}}{\partial r}\right), \\
& f_{\mathrm{Ma}} \frac{\partial q_{\mathrm{Ma}}}{\partial t}=\frac{f_{\mathrm{Ma}} D_{\mathrm{SMa}}}{r^{2}} \frac{\partial}{\partial r}\left(r^{2} \frac{\partial q_{\mathrm{Ma}}}{\partial r}\right)-R_{\mathrm{b}}, \\
& \left(1-f_{\mathrm{Ma}}\right) \frac{\partial q_{\mathrm{mi}}}{\partial t}=k_{\mathrm{bp}}\left(q_{\mathrm{Ma}}-q_{\mathrm{mi}}\right)=R_{\mathrm{b}} .
\end{aligned}
$$

In Eqs. (10)-(13), $q$ is the solid concentration of the adsorbate, $r$ is the intraparticle radial coordinate, $D_{\mathrm{s}}$ and $D_{\mathrm{p}}$ are the surface and pore diffusion coefficients, respectively, $C_{\mathrm{p}}$ is the adsorbate concentration of liquid in the pores, $f_{\mathrm{Ma}}$ is the volume fraction occupied by the macropore region, $D_{\mathrm{SMa}}$ is the surface diffusion coefficient on the macropore surface, $q_{\mathrm{Ma}}$ and $q_{\mathrm{mi}}$ are the solid concentrations of the adsorbate in the macropores and micropores, respectively, $R_{\mathrm{b}}$ is the rate of transfer of adsorbate from the macropores network to the micropores or branch pores, $k_{\mathrm{bp}}$ is the branch pore rate coefficient. The model results are shown in Table 3 and Figs. 4 and 5.

Fig. 4 indicates that, for all the three models used in this study, the branched pore kinetics model gives the best fit of the CSTR experimental data in the whole experimental period. Either the surface or pore diffusion model is able to describe well the early period of the adsorption kinetics, due to the neglect of the other part of the adsorption mechanism contributing to the adsorption capacity. Nevertheless, all three models satisfactorily fitted the data of the CSTR experiments with sufficient accuracy. The determination coefficients $R^{2}$ are between 0.98 and 0.999 . If the tortuosity $(\tau)$ of the activated carbon is estimated by using $\tau=1 / \varepsilon_{\mathrm{p}}$, then the value of $D_{\mathrm{p}}$ for the case of non-hindered diffusion (denoted as $D_{\text {pnh }}$ ) may be computed applying $D_{\text {pnh }}=\varepsilon_{\mathrm{p}} D_{\mathrm{L}} / \tau=\varepsilon_{\mathrm{p}}^{2} D_{\mathrm{L}}$. In Case I of $S_{\mathrm{PEG}, \mathrm{e}}$, substituting $\varepsilon_{\mathrm{p}}=0.54$ and $D_{\mathrm{L}}=0.9 \times 10^{-10} \mathrm{~m}^{2} / \mathrm{s}$ gives $D_{\mathrm{pnh}}=0.26 \times$ $10^{-10} \mathrm{~m}^{2} / \mathrm{s}$, which is smaller than $D_{\mathrm{p}}$ obtained by model simulation (denoted as $D_{\mathrm{pc}}$ with $D_{\mathrm{pc}}=2.9 \times 10^{-9} \mathrm{~m}^{2} / \mathrm{s}$ ). Similar results were obtained in Cases II-VI. The higher value of $D_{\mathrm{pc}}$ reflects the contribution of the additional intraparticle mass flux mechanism caused by the surface diffusion. In other words, the pore diffusion coefficient $\left(D_{\mathrm{pc}}\right)$ calculated by using the pore diffusion model in this study should be better regarded as the effective diffusion coefficient. Moreover, for large molecules (e.g., PEG), the surface diffusion may be of importance, due to multiple points of attachment of the molecule on the surface, which may lead to a decreased mobility of the molecule on the surface [3]. Therefore, it is not appropriate to describe the adsorption kinetics of PEG 

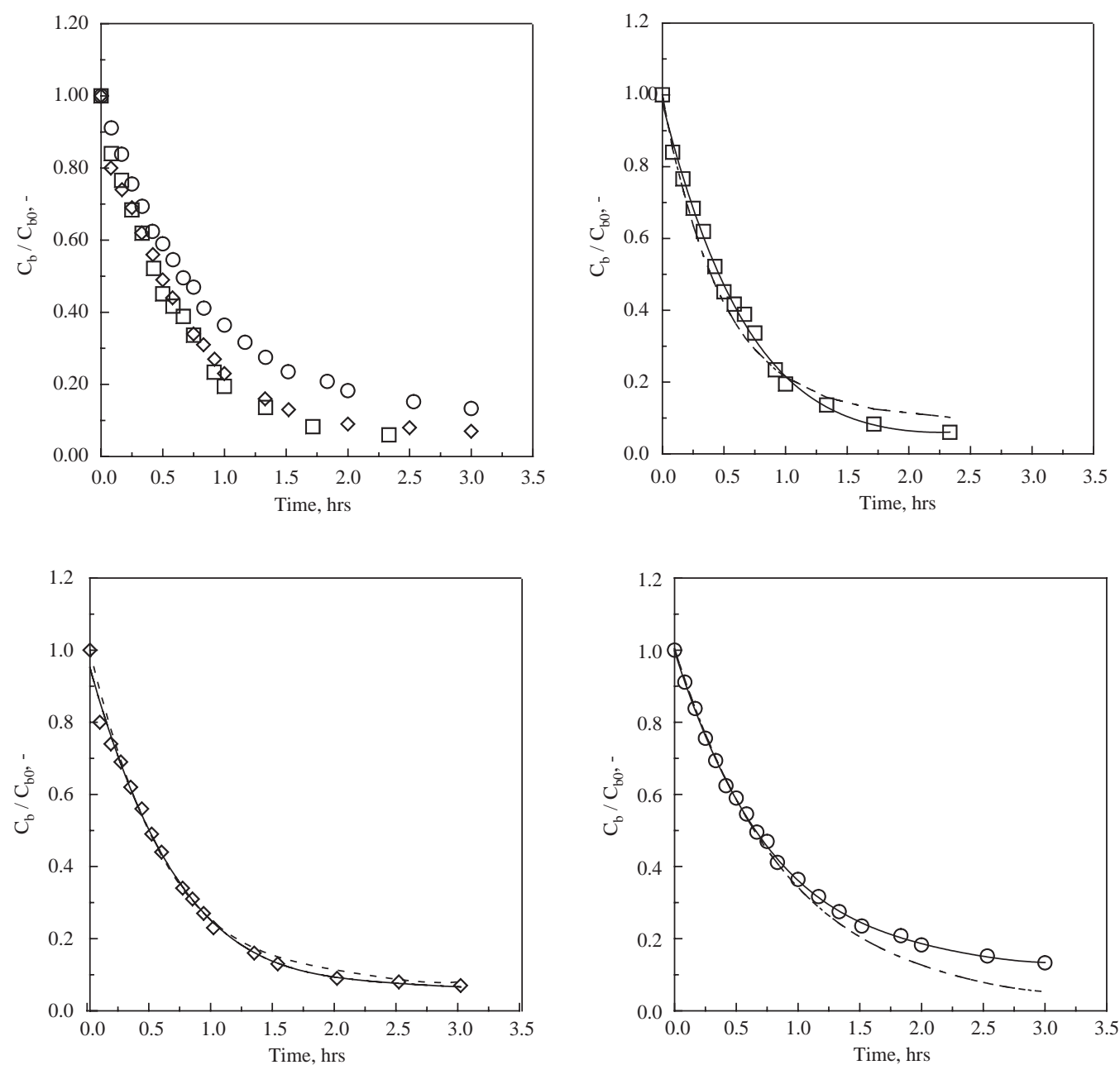

Fig. 4. Comparison of $C_{\mathrm{b}} / C_{\mathrm{b} 0}$ predicted by pore (- ), surface (--) and branch pore kinetics models (-) with experimental data for PEG adsorption on F-400 at same $C_{\mathrm{b} 0}$ of $50 \mathrm{~g} / \mathrm{m}^{3}$ in CSTR. $(\square),(\diamond)$, and $(\bigcirc)$ : Experimental data at $298 \mathrm{~K}$ in $S_{\mathrm{PEG}, 6.5}, S_{\mathrm{PEG}, 0.25}$, and $S_{\text {PEG,e }}$, respectively.

by using the pore diffusion model accompanied with the pore diffusion coefficient $\left(D_{\mathrm{p}}\right)$, unless $D_{\mathrm{p}}$ is regarded as an effective diffusion coefficient of the intraparticle diffusion including the contribution of both surface and pore diffusion.

The average pore diameter of F-400 of $18 \AA$ is smaller than the hydrodynamic diameters of PEG in all the three solutions (seen in Table 2). Although the multiple points of attachment of the hydrophobic segments on the surface may primarily contribute the adsorption of polymer PEG on F-400, the unadsorbed end of PEG may enter the pore with its front of smallest size facing the pore, then contact the surfaces of pores and also be adsorbed in the pore. As a result, a certain amount of PEG proceeds the adsorption in the micropores (i.e., $1-f_{\mathrm{Ma}}$ fraction in branched pore kinetics model). Comparing the results of Cases I-III, the fraction of
PEG adsorbed in the micropores in $S_{\text {PEG,e }}$ is largest. This may be due to the repulsion of adsorbed PEG molecules on the macropore surface which then forces the transport of PEG from macropore into micropore region.

Fig. 5 shows the effects of various initial concentrations $\left(C_{\mathrm{b} 0}\right)$ on the intraparticle diffusion. One single Langmuir equation can be used to satisfactorily describe the whole adsorption range on the excuse of rather high determination coefficients. The surface diffusion and the pore diffusion coefficients increase and decrease in the limited level with increase of $C_{\mathrm{b} 0}$, respectively. The increasing mobility of PEG on F-400 surface may be due to the occupation of weak energetic sites at high concentrations resulting in faster mass transfer rate. However, the decrease of pore diffusion coefficients can only be attributed to the thicker intraparticle diffusion 

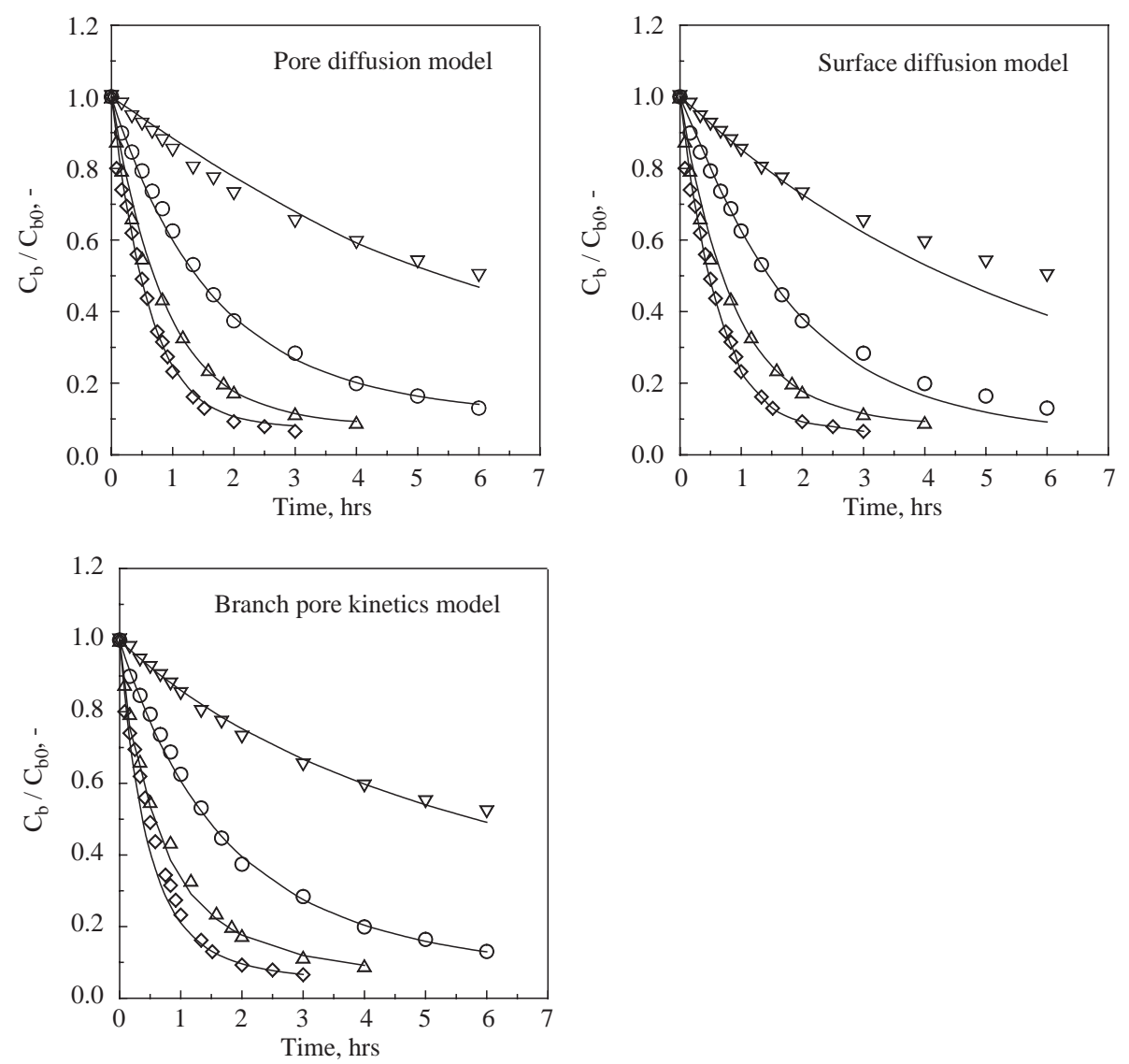

Fig. 5. Comparison of $C_{\mathrm{b}} / C_{\mathrm{b} 0}$ predicted by pore, surface and branch pore kinetics model (-) with experimental data for PEG adsorption on F-400 in CSTR. $(\diamond),(\triangle),(\bigcirc)$ and $(\nabla)$ : Experimental data of PEG adsorption in $S_{\mathrm{PEG}, 0.25}$ with $C_{\mathrm{b} 0}=50,100,200$, and $450 \mathrm{~g} / \mathrm{m}^{3}$, respectively.

layer at higher PEG concentrations. For further discussion of the predominant mass transfer resistance for the transport of PEG from the aqueous to the solid phase, the Biot number for the surface diffusion, $B i_{\mathrm{s}}(=$ $\left.k_{\mathrm{L}} d_{\mathrm{p}} C_{\mathrm{b} 0} / 2 D_{\mathrm{s}} \rho_{\mathrm{p}} q_{\mathrm{o}}\right)$, is examined to judge the relative influence of the external and internal mass transfer resistances. Film diffusion is considered to be the ratedetermining step for $B i_{\mathrm{s}}<1$, while the surface diffusion primarily controls the adsorption kinetics for $B i_{\mathrm{s}}>$ $50-100$ [3]. Thus, both external and intraparticle mass transfers have significant effects for $B i_{\mathrm{s}}$ in the range of 1-50. According to the values of $B i_{s}$, the rate-determining steps of the PEG adsorption from aqueous systems in this study can be divided into two groups: both film and surface diffusion control (e.g., Cases $I$ and $V I$ with $B i_{\mathrm{s}}$ values of 6 and 2, respectively), and sole surface diffusion control (e.g., Cases II, III, IV and $V$ with $B i_{\text {s }}$ values of 246, 396, 147 and 51, respectively). The results interpret that the film diffusion becomes important with the increasing $C_{\mathrm{b} 0}$ in $S_{\mathrm{PEG}, 0.25}$ and the interaction of the adsorbed/nonadsorbed PEG in $S_{\text {PEG,e }}$. In addition, the rough external surface of the adsorbent may also significantly cause the external mass transfer resistance even under intense stirring speed [18].

\section{Conclusions}

The adsorption behaviors of PEG on F-400 at low coverages seem similar in three solutions of $S_{\mathrm{PEG}, 6.5}$, $S_{\text {PEG,0.25 }}$ and $S_{\text {PEG,e }}$. However, the properties of solution (e.g., high ionic strength and lower $\mathrm{pH}$ value) have significantly negative effects on the adsorption of PEG in $S_{\mathrm{PEG}, \mathrm{e}}$ and $S_{\mathrm{PEG}, 0.25}$ when the adsorption approaches the plateau, due to the electrostatic repulsion and the strong steric repulsion between adsorbed PEG.

The liquid diffusivity can be obtained from the short plateau of the PEG adsorption breakthrough curve onto F-400 in $S_{\text {PEG,e }}$ in SFBR by means of the Gnielinski correlations. The internal mass transfer for the adsorption 
of PEG onto F-400 encountered in CSTR can be successfully interpreted by the surface, pore, and branched pore kinetics models. However, the pore diffusion coefficients obtained from the pore diffusion model should be regarded as the effective diffusion coefficients when compared with the non-hindered pore diffusion coefficients calculated from the liquid diffusivity.

The surface diffusion and the pore diffusion coefficients are increasing and decreasing in the limited level with increasing $C_{\mathrm{b} 0}$, respectively. The increasing mobility of PEG on F-400 surface may be due to the occupation of weak energetic sites at high concentrations resulting in faster mass transfer rate. However, the decreasing pore diffusion coefficients can only be attributed to the thicker intraparticle diffusion layer at higher PEG concentrations. The film diffusion becomes important with the increasing $C_{\mathrm{b} 0}$ in $S_{\mathrm{PEG}, 0.25}$ and the interaction of the adsorbed/nonadsorbed PEG in $S_{\text {PEG,e }}$. Therefore, both film and surface diffusion resistances, i.e., film-surface diffusion model, should be taken into account.

\section{Acknowledgements}

The authors would like to thank the sandwich program of NSC/DAAD (National Science Council of Taiwan/Deutscher Akademischer Austauschdienst) for Ph.D. candidates, and the Powder Technology Laboratory of the Chemical Engineering Department of National Taiwan University for the assistance in the powder characterization.

\section{Appendix}

The corresponding initial and boundary equations of the surface, pore, and branch pore kinetics models are described as follows:

For the surface diffusion model,

$q(r, 0)=0, \quad C_{\mathrm{p}}(r, 0)=0$,

$\frac{\partial q}{\partial r}=0 \quad$ at $r=0$ and $N_{\mathrm{L}}=-\left.D_{\mathrm{s}} \rho_{\mathrm{p}} \frac{\partial q}{\partial r}\right|_{r=d_{\mathrm{p}} / 2}=-\frac{d_{\mathrm{p}} \rho_{\mathrm{p}}}{6} \frac{\mathrm{d} \bar{q}}{\mathrm{~d} t}$,

$q\left(d_{\mathrm{p}} / 2, t\right)=q_{\mathrm{s}}, C_{\mathrm{p}}\left(d_{\mathrm{p}} / 2, t\right)=C_{\mathrm{s}}, q\left(d_{\mathrm{p}} / 2, t\right)=f\left(C_{\mathrm{s}}\right)$,

$V_{\mathrm{L}}\left(C_{\mathrm{b} 0}-C_{\mathrm{b}}\right)=m \bar{q}, \quad \bar{q}=\frac{3}{\left(d_{\mathrm{p}} / 2\right)^{3}} \int_{0}^{d_{\mathrm{p}} / 2} q r^{2} \mathrm{~d} r$.

For the pore diffusion model,

$C_{\mathrm{p}}(r, 0)=0, \quad q(r, 0)=0$,

$\left.\frac{\partial C_{\mathrm{p}}}{\partial r}\right|_{r=0}=0, \quad$ and $\quad N_{\mathrm{L}}=-\left.D_{\mathrm{p}} \frac{\partial C_{\mathrm{p}}}{\partial r}\right|_{r=d_{\mathrm{p}} / 2}$,
$q=f\left(C_{\mathrm{p}}\right), \quad V_{\mathrm{L}}\left(C_{\mathrm{b} 0}-C_{\mathrm{b}}\right)=m \bar{q}, \quad \bar{q}=\frac{3}{\left(d_{\mathrm{p}} / 2\right)^{3}} \int_{0}^{d_{\mathrm{p}} / 2} q r^{2} \mathrm{~d} r$.

For the branch pore kinetics model,

$q_{\mathrm{Ma}}(r, 0)=0, \quad q_{\mathrm{mi}}(r, 0)=0, \quad C_{\mathrm{b}}(0)=C_{\mathrm{b} 0}$,

$q_{\mathrm{Ma}}\left(d_{\mathrm{p}} / 2, t\right)=q_{\mathrm{s}}(t), \quad q_{\mathrm{s}}=f\left(C_{\mathrm{s}}\right)$,

$\frac{\partial q_{\mathrm{Ma}}}{\partial r}(0, t)=0$

$N_{\mathrm{L}}=-\left.f_{\mathrm{Ma}} D_{\mathrm{SMa}} \rho_{\mathrm{p}} \frac{\partial q_{\mathrm{Ma}}}{\partial r}\right|_{r=d_{\mathrm{p}} / 2}$,

$V_{\mathrm{L}}\left(C_{\mathrm{b} 0}-C_{\mathrm{b}}\right)=m \bar{q}, \quad \bar{q}=\frac{3}{\left(d_{\mathrm{p}} / 2\right)^{3}} \int_{0}^{d_{\mathrm{p}} / 2} q r^{2} \mathrm{~d} r$,

$q=f_{\mathrm{Ma}} q_{\mathrm{Ma}}+\left(1-f_{\mathrm{Ma}}\right) q_{\mathrm{mi}}$.

\section{References}

[1] Fang CL. General concepts of additives in the electroplating solution. Taipei, Taiwan: Finishing Science Publishers; 1996.

[2] Chang CF, Chang CY, Tsai WT. Adsorption equilibrium of polyethylene glycol in the copper electroplating solution on activated carbon. J Colloid Interface Sci 2000;232:207-9.

[3] Sontheimer H, Crittenden JC, Summers RS. Activated carbon for water treatment. Karlsruhe, Germany: DVGWForschungsstelle; 1988.

[4] Isabel R. Temperature dependence of the kinetics of activated carbon adsorption. Internship work performed at Heinrich-Sontheimer-Laboratory. Karlsruhe, Germany: DVGW-Technologiezentrum Wasser; 1998.

[5] Standen A, Executive Editor. Kirk-Othmer encyclopedia of chemical technology, 2nd ed. New York: Wiley; 1969.

[6] Cornel PK, Sontheimer H, Summers RS, Roberts PV. Sorption of dissolved organics from aqueous solution by polydtyrene resins-II. External and internal mass transfer. Chem Eng Sci 1986;41(7):1801-10.

[7] Gnielinski V. Gleichungen zur berechnung des waermeund stoffaustausches in durchstroemten ruhenden kugelschuettungen bei mittleren und grossen pecletzahlen. Verf Tech 1978;12(6):363-6.

[8] Streeter VL. Fluid mechanics, 8th ed. Singapore: McGrawHill; 1987.

[9] Chang CF, Chang CY, Höll H. Adsorption behavior of 2-naphthalenesulfonate on activated carbon from aqueous systems. Ind Eng Chem Res 2003;42:6904-10.

[10] Cussler EL. Diffusion: mass transfer in fluid systems. Cambridge, UK: Cambridge University Press; 1984.

[11] Polverari M, van de Ven TGM. Dilute aqueous poly (ethylene oxide) solutions: clusters and single molecules in thermodynamics equilibrium. J Phys Chem 1996;100: 13687-95.

[12] Wilke CR, Chang P. Correlation of diffusion coefficients in dilute solutions. AIChE J 1955;1(2):264-70. 
[13] Carberry JJ. A boundary-layer model of fluid-particle mass transfer in fixed beds. AIChE J 1960;6(3):460-3.

[14] Kataoka T, Yoshida H, Ueyama K. Mass transfer in laminar region between liquid and packing material surface in the packed bed. J Chem Eng Japan 1972;5(2): $132-6$.

[15] Kataoka T, Yoshida H, Ueyama K. Liquid phase mass transfer in ion exchange based on the hydraulic radius model. J Chem Eng Japan 1973;6(2):172-7.
[16] Peel RG, Benedek A. Dual rate kinetic model of fixed bed adsorber. J Environ Eng ASCE 1980;106(4): 797-813.

[17] Peel RG, Benedek A, Crowe CM. A branched pore kinetic model for activated carbon adsorption. AIChE J 1981; 27(1):26-32.

[18] Chatzopoulos D, Varma A, Irvine R. Activated carbon adsorption and desorption of toluene in the aqueous phase. AIChE J 1993;39(12;):2027-41. 